\title{
NOVO CORONAVÍRUS SARS-COV-2 E O AGRAVAMENTO DA INSEGURANÇA ALIMENTAR EM PAÍSES AFRICANOS COM HISTÓRICO DE EVENTOS CLIMÁTICOS E DE CONFLITOS ARMADOS
}

\author{
Maitu Abibo Buanango ${ }^{1}$ \\ Vladmir Antero Delgado Silves Ferreira ${ }^{2}$ \\ Maria Rita Marques de Oliveira ${ }^{3}$
}

\begin{abstract}
Resumo
Em tempos de crise, uma das áreas fortemente afetada tem sido a alimentação, como consequência direta dos estragos causados na agricultura familiar e por conseguinte na Segurança Alimentar e Nutricional (SAN). As mudanças climáticas, por sua vez originam crises generalizadas, que pelo seu impacto na humanidade, e sobretudo, na SAN, propiciam crises humanitárias complexas, agravando-se a fome. O conflito militar impõe dificuldades no acesso aos alimentos e na produção. Este estudo teve como objetivo descrever criticamente o panorama das mudanças climáticas e conflitos armados em África, relacionando-os à pandemia da COVID-19 como fator de agravamento da situação de insegurança alimentar em países africanos. Foi realizado um estudo de revisão de literatura em várias bases de dados, periódicos e portais para o efeito, com destaque para Google Académico, Portais CAPES e governamentais. Os resultados apontam para mudanças climáticas, como sendo multicausais, e constituem fator de risco para a agricultura e SAN, nos países africanos, caracterizadas por destruição de culturas e a diminuição da disponibilidade de alimentos. Os conflitos armados dificultam a produção e distribuição de alimentos, sobretudo, para as pessoas afetadas.
\end{abstract}

Palavras-chave: Segurança Alimentar; Mudanças climáticas; África; Pandemia; Crises.

\section{Introdução}

Os desastres são eventos que expõem um significativo número de pessoas a perigos com danos físicos e materiais, perda de vidas ou devastação ambiental, podendo atingir estados de

\footnotetext{
${ }^{1}$ Faculdade de Ciências Farmacêuticas, Universidade Estadual Paulista "Júlio de Mesquita Filho" - UNESP, Campus de Araraquara, São Paulo, Brasil; e Universidade Zambeze - UniZambeze, Campus de Matacuane, Beira, Moçambique. Orcid: https://orcid.org/0000-0002-3828-7866

${ }^{2}$ Escola de Ciências Agrárias e Ambientais, Universidade de Cabo Verde, UNICV, São Jorge, Cabo Verde. Orcid: https://orcid.org/0000-0002-1660-0460.

${ }^{3}$ Departamento de Ciências Humanas e Ciências da Nutrição e Alimentação, Instituto de Biociências, Universidade Estadual Paulista "Júlio de Mesquita Filho" - UNESP, Campus de Botucatu, São Paulo, Brasil. Orcid: https://orcid.org/0000-0003-1226-4364.
} 
catástrofe ou calamidade, afetando populações vulnerabilizadas. Os desastres podem ser provocados por fenômenos naturais ou antropogênicos, estes últimos resultantes de obras humanas (PARK; TAGLES, 2011).

A pandemia da COVID-19 causada pelo novo coronavírus SARS-Cov-2 se caracteriza como um desastre natural de ordem biológica, uma doença zoonótica, transmitida de animais para humanos (OMS, 2020) e, especula-se, que possa estar associada às formas de exploração da natureza pelo homem (UNEP, 2016). O risco de contaminação é real e universal, dada a velocidade com que o vírus vem sendo transmitido entre os humanos. No entanto, a depender das estruturas e contextos geográficos, sociais e históricos, as condições para o seu enfrentamento são desiguais e, para muitos, o acesso aos serviços de saúde e gêneros de primeira necessidade não chegam (MOREIRA et al., 2020). No caso de populações africanas, soma-se ao SARS-Cov-2 outras ameaças naturais e antropogênicas que, se de um lado a nova ameaça pode surgir diluída entre outras tantas, de outro pode agravar um cenário que já não era favorável, frente às mudanças climáticas e eventos associados aos conflitos armados (ORGANIZAÇÃO DAS NAÇÕES UNIDAS, 2020).

África foi identificada como uma das regiões mais vulneráveis aos impactos das mudanças climáticas, devido a vários fatores, como alta taxa de crescimento populacional, proliferação de favelas (assentamentos informais), fraco acesso aos recursos económicos e agregados chefiados por mulheres e crianças, tidos como os mais vulneráveis economicamente (N'GOMBE; TEMBO; MASASI, 2020; MUTTARAK, 2017).

Neste sentido prevê-se consequências graves, pelos impactos de longo alcance que se podem exercer nos meios de subsistência de muitas pessoas. Resultados de estudos feitos em África apontam que as mudanças climáticas têm elevado impacto negativo nas terras agrícolas, o que acaba reduzindo a produção e afetando a SAN. É preocupante o fato de que muitas comunidades rurais que dependem da agricultura familiar, enfrentem insegurança alimentar induzida por desastres relacionados ao clima (MASIPA, 2017).

Para além das ameaças climáticas, países que tiveram conflitos armados em seus territórios, registaram milhares de vítimas mortais e deslocados, que forçaram ações como o desmatamento para a sobrevivência, e as respetivas implicações na piora da situação de SAN. Alguns países conseguiram sair deste ciclo de conflitos, mas outros ainda permanecem nele, como adiante se 
poderá depreender. Em suma, a perda de capacidade de produção pode ocasionar crises de insegurança alimentar e nutricional, face à ocorrência de conflitos armados, como acontece em muitos países africanos, alguns dos quais destacados ao longo deste trabalho.

Além do mais, não se pode ignorar a condição de bloqueio económico, que frequentemente atinge os países que não se submetem às políticas de grandes potências económicas e militares.

Igualmente, a fome, independentemente do lugar prejudica a paz em todos os locais. As estratégias internacionais foram criadas para operar como o padrão comum de guerra de Estado contra Estado, no século passado. Em contrapartida, muitos dos conflitos novos têm importantes características regionais e internacionais. A luta contra o terrorismo atinge vários países, incluindo Moçambique (MACHADO, 2017). É necessário que os organismos internacionais se reinventem e passem a prestar apoio às vítimas de deslocamento por terrorismo, por se tratar de um problema global e que requer igualmente soluções locais e globais.

É em meio a esse cenário que o SARS-Cov-2 chegou à muitos dos países da África. E temese um agravamento da insegurança alimentar ocasionado pela privação das comunidades ao exercício de suas atividades diárias que lhes garantem o sustento e à crise econômica que pode interferir na economia dos países e nas relações externas.

O conceito de Segurança Alimentar e Nutricional, associa-se à outros dois conceitos, o de Direito Humano à Alimentação Adequada (DHAA), garantido no Pacto Internacional dos Direitos Econômicos, Sociais e Culturais, conforme orienta o seu Comentário no 12 (ORGANIZAÇÃO DAS NAÇÕES UNIDAS, 1999) e ao conceito de soberania alimentar, que diz respeito à autonomia e direito à produção do alimento.

O conceito de SAN adotado pela maioria dos países surgiu na Cúpula Mundial de Alimentação, realizada pela Organização das Nações Unidas para Alimentação e Agricultura (FAO), em 1996, considerando que o direito à alimentação adequada é alcançado quando todos os homens, mulheres e crianças, sozinhos, ou em comunidade com outros, têm acesso físico e econômico, em todos os momentos, à alimentação adequada, ou meios para sua obtenção. O direito à alimentação adequada não deve ser interpretado como um pacote mínimo de calorias, proteínas e outros nutrientes específicos. A adequação refere-se também às condições sociais, econômicas, culturais, climáticas, ecológicas, entre outras. 
O conceito de SAN abarca 4 dimensões: disponibilidade, acesso, uso e estabilidade, sendo esta última transversal às três primeiras. Assim, almejam-se alimentos de qualidade disponíveis e universalmente acessíveis que promovam saúde e bem-estar dos povos sem comprometer a vida do e no planeta. As mudanças climáticas comprometem a realização de todas as dimensões da SAN, tornando cada vez maiores os desafios para os sistemas agrícolas de subsistência (DODD et al., 2020)

Diante do exposto, o objetivo foi descrever criticamente o panorama das mudanças climáticas e conflitos armados em África, relacionando-os à pandemia da COVID-19 como fator de agravamento da situação de insegurança alimentar em países africanos. Para o efeito o estudo baseou-se numa revisão de literatura. Num primeiro momento apresenta-se o panorama sobre as mudanças climáticas e conflitos armados em países que experimentaram conflitos internos e catástrofes naturais, num segundo momento busca-se explorar as implicações do novo coronavírus SARS-Cov-2 nesses cenários, apontadas medidas que, se fossem adotadas, poderiam mitigar a insegurança alimentar das populações expostas a esses cenários.

\section{Metodologia}

Foi realizada uma revisão crítica da literatura buscando articular conhecimentos sobre mudanças climáticas, conflitos armados e aspectos epidemiológicos do SARS-CoV-2. Para o levantamento bibliográfico foram utilizadas as seguintes estratégia de busca: "África” AND "Food Security" AND "armed conflict" AND "climate change" e o correspondente em português nos últimos 5 anos, ordenados nas bases de dados por relevância. Outra busca foi realizada com os termos "SARS-CoV-2" OR “COVID-19" OR "novo coronavírus". As bases de dados utilizadas foram o Google Académico e o Portal CAPES. Nas bases de dados, os artigos foram selecionados primeiro pelo título, depois pelo resumo e finalmente pela leitura integral, na ordem em que apareceram nas bases e conforme a disponibilidade de acesso, convenientemente, em volume de informações e dados suficientes ao propósito dos autores. Foram também consultados documentos de Portais da União Africana, dos Governos dos países africanos analisados e da OMS. Os artigos foram lidos buscando as ideias centrais e a relação estabelecida pelos autores com a SAN e outras informações relevantes para sustentar a argumentação. 


\section{Resultados e Discussão}

O crescimento da produtividade agrícola é vital para os resultados económicos e de segurança alimentar (MICHLER et al., 2019), e os fatores que contribuem para a insegurança alimentar e o risco de desastres são complexos, porquanto, o impacto de cada um influencia os resultados da saúde e não só (CLAY et al., 2018). A seguir, trataremos por questões didáticas, as mudanças climáticas, os conflitos armados em sessões separadas, para ao final fazer um ensaio de conexão entre estes e a pandemia de COVID-19.

\section{Mudanças climáticas como causa de insegurança alimentar}

As mudanças climáticas representam um problema global, cuja solução exige cooperação global. A verdade é que, metade ou mais de danos humanos hoje associados às mudanças climáticas poderiam ser evitados. Medidas que reduzam os impactos das mudanças climáticas na saúde são as mais eficazes, seguidas por aquelas que diminuem a exposição às condições meteorológicas extremas. Igualmente, a substituição de meios de produção intensivos em carbono, transporte e criação de energia ou evitar o desmatamento podem mitigar a situação (MUKAMUHIRWA et al., 2019; CLIMATE VULNERABLE FORUM, 2010). É necessária a ampliação do uso de matéria orgânica para evitar queima e criação de emissões e gases na atmosfera, o uso efetivo de esterco de gado e o uso de variedades de sementes apropriadas e adaptáveis, gerenciando o esterco de gado para auxiliar na cobertura, e reduzir a perda de água através da evaporação e usando sementes adaptáveis (ZWANE, 2019).

Não só as atividades extensivas para a produção de comodities do setor agropecuário são ameaças ao equilíbrio ambiental, mas também a exploração de outros recursos naturais, como é o caso da mineração, em que grandes empreendimentos têm desalojado as comunidades locais, criando situações de instabilidade e insegurança alimentar (FERREIRA, 2016; ALIER, 2007)

De 2010 a 2030 prevê-se 5 milhões de mortes. E, ainda, a partir de 2030, a cada ano, 1 milhão de pessoas poderão morrer caso haja ausência de uma resposta eficaz face às mudanças climáticas. Ao contrário do que se pensa, a maioria de mortes humanas ligadas às mudanças climáticas não são causadas por tempestades fortes ou inundações, mas sim, são resultantes de doenças sensíveis ao clima. Cifras de milhões de doenças a cada ano são a estimativa, 
principalmente devido à desnutrição, infecções diarreicas e malária (CLIMATE VULNERABLE FORUM, 2010).

Para manter a SAN de suas famílias, os agricultores de subsistência em todo o mundo enfrentam o desafio contínuo de equilibrar a produção agrícola para ambos os setores de sustentação e renda, com pouca ou nenhuma tecnologia e assistência técnica (DODD et al., 2020).

Apesar de resultados de estudos mostrarem que não há um fator único que cause mudanças climáticas. As indicações da literatura são de que humanos e não humanos podem causar mudanças climáticas (ZWANE, 2019), estas que têm sérios impactos nas terras agrícolas, o que acaba afetando a SAN (MASIPA, 2017), e tem sido comum associá-las aos extremos de temperatura em todo o mundo (KAPWATA et al., 2018).

As mudanças climáticas reduzem o acesso à água potável, afetam negativamente a saúde das pessoas e representam uma série de ameaças à SAN (MUGAMBIWA; TIRIVANGASI, 2017), e apresentam uma influência negativa na produção agrícola, como resultantes de tendências crescentes de temperatura, associadas às mudanças extremas em todo o mundo (KAPWATA et al., 2018).

Pesquisas sugerem ainda que a região africana será submetida aos extremos de calor mais intensos por um período mais curto, com projeções prevendo aumentos de $4-6^{0} \mathrm{C}$ para o período 2071-2100, nas temperaturas máximas médias anuais para o sul da África (KAPWATA et al., 2018). E, o impacto de mudanças climáticas, bem como a suscetibilidade das comunidades pobres, é muito intenso (MUGAMBIWA, 2017).

As mudanças climáticas causam anualmente números elevados de mortes, conforme refere o Relatório de Climate Vulnerable Forum (2010, p.12), que indica para,

(...) 350.000 mortes, e estima-se que as tempestades, inundações e incêndios florestais provoquem danos a cada ano, de mais de 5 bilhões de dólares, e o aumento dos níveis de mar custe $1 \%$ do PIB para os países de baixa renda. Globalmente, os setores primários e a pesca investem 65 bilhões de dólares, anualmente, devido ao estresse climático. A maioria dos impactos é altamente concentrada, especialmente, em crianças e pobres. Sendo que mais de três quartos do número de mortes relacionadas às mudanças climáticas são concentrados em crianças que vivem na África Subsaariana ou no Sul da Ásia. Cerca de 50 países são considerados extremamente vulneráveis ao clima hoje, sofrendo coletivamente a maior parte de todos os impactos. Entre eles estão os países africanos como a Serra leoa e Somália, agravados pelo surgimento de conflitos armados. 
Uma outra dimensão de impactos refere que as mudanças climáticas contribuem para o agravamento das desigualdades globais, tendo em conta que, em geral, são mais desvantajosas, para os pobres e mais vantajosas para os ricos. O estresse adicional prejudicará a produção e o crescimento económico. Os pré-existentes desafios ambientais, diante das mudanças climáticas, aceleram as suas consequências. Na maioria dos casos, os impactos económicos das mudanças climáticas estão realmente tornando os ricos mais ricos, por exemplo, em alguns setores do norte da Europa. As piores perdas estão sendo sentidas em países que já são pobres, especialmente em África. E, globalmente, os estresses económicos resultantes de eventos naturais apontam perdas de 63 bilhões de dólares a cada ano. Esse impacto aumentará em mais de $100 \%$ à 157 milhões anualmente até 2030 (CLIMATE VULNERABLE FORUM, 2010).

São inúmeros os efeitos potenciais que as mudanças climáticas podem ter na agricultura, conforme tivemos a oportunidade de referenciar anteriormente. Porém, uma outra dimensão do impacto dos desastres é a que afeta o crescimento das culturas, sua qualidade e a saúde dos animais. O que significa que tanto as práticas agrícolas, como a pecuária devem constituir motivo para a preocupação. A suscetibilidade das comunidades pobres às mudanças climáticas é muito intensa (MUGAMBIWA; TIRIVANGASI, 2017). No entanto, mesmo assim, ainda existem evidências comparáveis limitadas em vários países e regiões sobre a extensão global dos choques climáticos que afetam a SAN dos pequenos agricultores (NILES; SALERMO, 2018). Sendo que, nalgumas regiões de África do Sul, em 2017, estragos provocados por surtos de lagartos, a seca e o calor afetaram a qualidade das frutas e tamanho, queimaduras solares, cor e capacidade de armazenamento, tendo diminuído a demanda nos principais mercados. Uma tendência semelhante foi observada na produção de vegetais, tendo empresas chegado a fechar, por causas das mudanças climáticas. A produção de cebolas e batatas foi abaixo de $50 \%$ e $80 \%$, respectivamente, por falta de água. Essa redução na produção traduz-se em perda de 40 milhões de salários para trabalhadores sazonais (MUKAMUHIRWA et al., 2019).

Sendo que a água é também alvo dos impactos das mudanças climáticas, em relação a ela, num outro estudo realizado na África do Sul concluiu-se que, muitas barragens apresentaram em baixos níveis de água (40\%), durante 2016/2017, o que reduziu o rendimento de culturas. As secas que afetaram pequenos agricultores e agricultores, passaram a ser um fenómeno comum. A 
produção pecuária decresceu ao longo do tempo, com pequenos estoques, sendo a indústria de carne bovina e leiteira a mais afetada (ZWANE, 2019).

Em 2019, Moçambique, Malawi e Zimbabué registaram a ocorrência de Ciclone Idai que causou enormes prejuízos, incluindo perdas de culturas produzidas no âmbito da agricultura familiar. Em Malawi, 868.900 pessoas foram afetadas por aquele ciclone, incluindo 87000 pessoas deslocadas internamente, das quais mais de 60\% eram mulheres e crianças (USAID, 2019). E, logo após ao ciclone Idai, Moçambique foi assolado por outro ciclone denominado kenneth (MANJORO; ROSSE; FERREIRA, 2020).

Moçambique é um país propenso à ocorrência desastres naturais tais como cheias e ciclones. As alterações climáticas estão a aumentar os riscos destes desastres. Os números são altamente alarmantes. Entre 1970 e 2009, este país foi atingido por 77 desastres naturais, dos quais 41 ocorreram entre 2000 e 2009 (REPÚBLICA DE MOÇAMBIQUE, 2017). Numa altura em que especialistas alertam que,

Eventos extremos como ciclones, altas temperaturas, enchentes e secas serão ainda mais frequentes no futuro próximo. É provável que certas áreas do mundo se tornem lugares inóspitos para a vida humana, fazendo com que as medidas de adaptação, incluindo reassentamento de pessoas, tenham que ser uma prioridade nas agendas dos Estados (JACOBS; ALMEIDA, 2020, p. 3).

De acordo com o Instituto Humanitas Unisino (2017, p. 2),

Secas prolongadas correm o risco de expor à falta de água até 250 milhões de africanos até 2020. E, em 2040, de acordo com o Banco Mundial, de 40 a $80 \%$ da superfície da África subsaariana destinada ao cultivo de cereais, tais como trigo e milho, poderiam sofrer intensa deterioração tornando-se inaproveitáveis. Chuvas fracas e irregulares são uma ameaça constante para o Corno de África e outras partes da África oriental. A fome na Somália de 2011, que matou 250.000 pessoas, e a atual crise de alimentos no Corno, podem ser atribuídas a uma seca prolongada que levou à colheitas desastrosas, além de dizimar o gado (...) Na emergência em curso, as estimativas mais recentes apontam que entre Somália, Quénia e Etiópia, 14,4 milhões de pessoas sofrem de "insegurança alimentar aguda" e precisam de assistência humanitária imediata. Enquanto quase três milhões de somalis já estão a um passo da carestia absoluta. (...) A região do Sahel, faixa de terra semi-árida logo abaixo do deserto do Saara, parece mais vulnerável. A mudança climática também incide sobre um quadro político e econômico já bastante precário. A região tem uma imensa 
extensão - da Mauritânia ao Eritreia - e apresenta um forte crescimento populacional; atualmente soma 135 milhões de habitantes, mas poderia chegar a 330 milhões em 2050, e quase 670 milhões em 2100.

Todos os anos, centenas de milhares de migrantes atravessam essas áreas instáveis e empobrecidas para alcançar o Norte de África, e depois, eventualmente, à Europa. O debate sobre o tema permanece em aberto. No entanto, a maioria dos estudos parece concluir que o aumento da temperatura, de 3 a 5 graus a mais até 2050, e talvez 8 graus até o final do século, vai tornar muitas áreas do Sahel ainda mais inóspitas, intensificando a ocorrência das migrações. (UNIÃO AFRICANA, 2014). O aumento das temperaturas poderia causar um declínio na produção agrícola, que vai de 13\% em Burkina Faso a 50\% no Sudão. Outras pesquisas, mais pessimistas, especulam autênticos apocalipses (IHU, 2017, p. 2)

E, uma das consequências mais diretas do genocídio ora referido foi no setor da agricultura familiar. Este que era considerado fonte de renda mais importante antes do genocídio $(75 \%)$ e depois, as famílias envolvidas na agricultura diminuíram para 57\%, devido a escassez de terra para os migrantes das áreas rurais que se mudaram para as áreas urbanas. E, como em outros genocídios no mundo, o de Ruanda era complexo, com causas e efeitos multidimensionais, nomeadamente: ambientais, como a escassez de terra, as crescentes pressões da população sobre a terra apenas agravaram as circunstâncias que levaram ao genocídio. O impacto ambiental mais premente em Ruanda é o aumento do desmatamento para fins de construção de moradias, construção de novas instalações, uso de madeira para energia e, mais importante, limpeza de áreas florestais para fins agrícolas (MOODLEY; GAHIMA; MUNIEN, 2011).

Ainda sobre Ruanda, dados indicam que as florestas diminuíram em tamanho para atender às necessidades da população em crescimento e para propósitos de reassentamento. Além disso, fatores como extração ilegal de madeira e corte de árvores, produção de carvão vegetal, práticas agrícolas, mineração, apicultura e incêndios florestais apresentam impacto nas reservas florestais (RWANDA, 2011)

Assim, verifica-se que os eventos naturais afetam diretamente os pequenos agricultores do mundo em desenvolvimento, ameaçando a SAN das famílias (NILES; SALERMO, 2018). Em áreas, por exemplo, onde a irrigação é insuficiente, as culturas murcham e morrem, reduzindo assim o rendimento, podendo significar aumento da pobreza (AFFUL, 2016), num contexto em que a 
agricultura é a base de economia da maioria dos países africanos (STEVENS; MADANI, 2016). Se não forem tomadas medidas necessárias, estima-se que até 2030, 42 países se tornariam extremamente vulneráveis aos impactos das mudanças climáticas (CLIMATE VULNERABLE FORUM, 2010).

O enfrentamento deste problema exige grande esforço, com envolvimento de muitos atores. Resultados de estudos apontam para a necessidade de ações intersetoriais sobre equipas de atenção básica, a agricultura e educação para enfrentar os resultados adversos das mudanças climáticas (SCHEERENS et al., 2020).

\section{Conflitos armados internos como causas da insegurança alimentar}

A guerra civil é a que acontece somente dentro de um Estado, e são orquestradas por grupos organizados. Esses grupos se organizam através de etnias ou de ideologias que de modo geral se transformam nos motivos pelos quais essas guerras ocorrem. Dessa forma elas são opostas às guerras institucionalizadas ou totais, onde existia atuação de mais de um Estado (MACHADO, 2017, p. 14).

É de se notar que frequentemente, essas guerras ocorrem em países do terceiro Mundo, dado que são países com independência tardia. Nitidamente, a história, o povo, a etnia e várias outras particularidades destes países, são totalmente opostas às dos seus colonizadores (HOLSTI, 1996).

Com a criação de um Estado nos modelos dos países colonizadores, não foram considerados os meios sociais das regiões com as quais estavam usando. Dessa forma, dividiram várias etnias em territórios diferentes e que posteriormente se tornaram países diferentes após a realização do que planejavam, ou juntar etnias inimigas em um só país. Essas separações ou união de povos diferentes fizeram com que o Estado tivesse muita dificuldade ao desempenhar seu papel no momento em que esses países se tornaram independentes de suas colónias, contribuindo para que as resoluções dos conflitos se tornassem muito mais complexas (MACHADO, 2017).

Os motivos dos conflitos armados podem ter diversas razões, e elas vão depender da característica particular de cada Estado, em consequência do seu próprio contexto interno, povo, regime político, economia ou religião. As questões de migração, de fluxos repentinos de refugiados e principalmente a questão da insegurança alimentar, além de sofrerem com secas, que reduzem 
drasticamente a produção de alimentos, e dessa forma aumentam os problemas internos dos países e intensificam os conflitos armados internos (MACHADO, 2017).

A exemplo, um conflito étnico racial eclodiu em Burundi, país vizinho de Ruanda. Duzentas mil pessoas morreram durante o genocídio. Burundi hoje tem cidadãos em insegurança alimentar, sua situação é frágil, temendo-se a eclosão de mais eventos violentos, pois a fome gera violência. E, a insegurança alimentar gera descontentamento, atribuindo-se a incapacidade ao governo de proporcionar um ambiente estável para a prosperidade. Isso leva a maioria pobre hutu a apoiar a Força de Libertação que por sua vez desestabiliza o país. Então isso alimenta mais violência em um país já empobrecido e instável (YAKLIN, 2017).

Consistente com essa situação, Sitoe (2019, p. 2) refere que,

África tem sido historicamente um continente conturbado. Se a partir do ano 1940 começou a se livrar das amarras do colonialismo, os anos seguintes foram caracterizados por vários conflitos intra-estatais ou guerras civis do período pós-independência que muitas vezes estiveram associados a fatores identitários e exploração dos recursos naturais. (..) A partir dos anos 2000 um novo fenómeno começou a predominar e a caracterizar a já complexa estrutura de conflitos no continente, o terrorismo, sobretudo com a emergência de dois grandes grupos, o Boko Haram e o Al-Shabaab, na Nigéria e Somália, respetivamente. Se o espetro do terrorismo parecia circunscrever-se às contiguidades dos dois Estados hospedeiros destes dois movimentos, o ano 2017 mostrou que o terrorismo poderia estar mais próximo de Moçambique do que se podia imaginar. Isso se revelou com os primeiros ataques realizados na região nortenha de Mocímboa da Praia, em Cabo Delgado, um cinturão estratégico para o desenvolvimento do Estado moçambicano.

Se ainda havia dúvidas sobre quem seriam os protagonistas, recentemente, o governo moçambicano assumiu publicamente, pela primeira vez, que Moçambique está diante de incursões de terrorismo internacional, protagonizadas por insurgentes extremistas do Estado Islâmico (MOÇAMBIQUE..., 2020).

Acontece que, dois anos depois do começo dos primeiros ataques da insurgência armada, a mesma deixou mais de 1100 mortos e já forçou cerca de 200 mil deslocados, sendo que a situação parece estar ainda longe de ser controlada pelas autoridades (INSURGIÊNCIA..., 2000).

Nas zonas onde há incursões de grupos armados, várias pessoas estão deslocadas e reportaram situações de fome, aliado a pandemia da COVID-19, a situação poderá ser catastrófica, 
pois as pessoas deixaram tudo quanto tinham, suas plantações em busca de locais seguros. Não há ainda apoios alimentares às famílias que se deslocaram, estando em clara situação de insegurança alimentar.

A SAN é dever e obrigação das autoridades políticas de cada território. Consequentemente, sendo obrigação dos Estados e mais amplamente de toda a sociedade civil, as crises de fome incidem como uma violação dos direitos universais dos indivíduos, porque acabam reduzindo as perspectivas da dignidade humana (DALLARI, 2000). Deveria haver alguma ação do Estado para prestar assistência àquelas famílias que foram deslocadas, não por vontade própria, mas decorrente do contexto que lhes foi imposto. Este posicionamento é coerente com o Primeiro Protocolo de Convenções de Genebra, ao indicar que grupo que tiver o poder no país em conflito, possui a obrigação de assegurar alimentos para toda a população civil e precisa levar alimentos que são essenciais, produtos médicos e outros itens (ZIEGLER et al, 2011; MACHADO, 2017).

Outro país que também foi profundamente marcado por conflitos violentos, conforme nos referimos anteriormente é a Somália. A inexistência de um governo central neste país propiciou o surgimento de lutas internas pelo poder, através de facções rivais, e aumentaram os conflitos em maiores proporções. E, devido a caos instaurado, a agricultura não permitiu uma colheita, levando a população à fome e às doenças (RODRGUES, 2000; MACHADO, 2017).

Os vestígios de conflitos deixaram destruídas a agricultura e pecuária, e estima-se que 1992, morreram trezentas mil a trezentas e cinquenta mil pessoas por fome na Somália, para além das 14 mil mortas diretamente pelo conflito (WHEELER, 2000), adicionando ao conflito, houve seca que destruiu a região inteira, criando uma crise alimentícia, com cerca de 250.000 vítimas, sendo que muitos adoeceram e morreram devido a falta de alimentos (RODRIGUES, 2000; KAPTEIJNS, 2013).

A morte de milhares de pessoas na Somália é vista não como causa de falta de assistência, mas de má distribuição dela, resultante de dificuldades impostas para a canalização de auxílio humanitário suficiente de maneira rápida, dado que não existia lei vigente no território (WHEELER, 2000).

Quando existe uma situação grave de fome ou insegurança alimentar generalizada, os conflitos se intensificam. Intensificam-se, também, os conflitos pela terra, pela água e pelo alimento. O período de grande insegurança alimentar pode originar revoltas sociais graves. Com 
riscos à própria governabilidade. Por isso, é totalmente provável que uma ameaça à SAN tenha grande impacto na própria segurança do Estado. Portanto, garantir a SAN é fundamental não apenas para o próprio interesse do país em preservar condições apropriadas à sua população, assim como à sua própria existência como tal (MACHADO, 2017).

A Somália é um bom exemplo de o quanto a confluência de factores é prejudicial para a SAN. Na agricultura, os resultados sempre foram inferiores, em consequência do clima árido da região. Ao longo do tempo, a população passa aumentar, porém, os rendimentos possivelmente permanecem os mesmos. A gravidade é ainda maior porque o aquecimento global do Oceano Índico diminuiu a precipitação das chuvas esperadas durante a Primavera, e as terras são cada vez menos adequadas para a produção agrícola, o que aumenta a insegurança alimentar da população. A alta nos preços dos alimentos também foi um fator grave porque empobreceu as populações rurais que perderam seu gado e seus rendimentos agrícolas, ao mesmo tempo em que os preços continuavam a subir (MACK, 2008).

Mesmo sendo uma grave violação dos direitos humanos, ainda é grande a utilização de comida como arma de guerra no continente africano (MACHADO, 2017), a Somália e alguns países independentes da Antiga União Soviética, são exemplos de países em conflitos que utilizaram comida como arma de guerra. E, a escassez de alimentos afeta os preços e junto com baixa produção, intensifica a vulnerabilidade do mercado interno, prejudicando os exportadores e pequenos proprietários (BORA et al., 2010).

Os conflitos armados internos impedem a produção, os mercados e a distribuição agrícola, piorando a situação. Nessas condições, os alimentos passam a ser utilizados como arma política para provocar e prolongar o combate, causando ainda mais o prejuízo à SAN (MACHADO, 2017).

Outra consequência dos conflitos armados na insegurança alimentar, é o deslocamento de pessoas, que intensifica a ameaça no ambiente em que eles se refugiam, gerando uma destruição ambiental. Ou seja, quanto maior for a concentração de pessoas, maior será a procura por recursos como forma de sobrevivência. Além do mais, os conflitos modificam toda a organização social das comunidades, os laços familiares e a estrutura das propriedades. A falta de segurança nessas condições não permite a criação de condições para um desenvolvimento constante e com benefícios para toda a nação. A população passa a precisar de ajuda do governo ou exterior, como em casos de doação de alimentos e medicamentos, não possuindo estabilidade e até mesmo liberdade, como 
aquelas presas em campos de refugiados ou reféns. O indivíduo que se vê sujeito à condição de refugiado dentro do seu próprio país, já traz em si, a violação de direito humano essencial (MACHADO, 2017).

Entretanto, em alguns estudos, realizados no Gana, por exemplo, o primeiro país africano a tornar-se independente, apontam que os ganhos de calorias foram eliminados das perdas nas calorias consumíveis da mandioca, levando à reduções gerais nas calorias consumíveis dos alimentos. No geral, em toda a África subsaariana, a redução de todas as calorias consumidas ocorre em média anualmente devido as mudanças climáticas (ZWANE, 2019)

Em Ruanda, um estudo que avaliou o impacto de esforços simultâneos de seca e temperatura no crescimento concluiu que o desenvolvimento da planta e seu rendimento foram altamente influenciados pela seca (MUKAMUHIRWA et al., 2019). Outro estudo sobre o Ruanda, realizado por Moodley; Gahima; Munien (2011, p. 112), refere que,

Ruanda tem uma das maiores taxas de desmatamento da África central, devido à grande escassez de terra, uma questão crítica que contribuiu para o genocídio nos anos 90, conflito étnico racial. Após ao genocídio, ocorre limpeza em massa e a remoção de florestas, com objetivo de disponibilizar mais terras para a realocação de refugiados e pessoas deslocadas, lenha, extracção de madeira para assentamentos e construção de estradas. Além disso, o excesso de pasto e o cultivo levaram ao desmatamento. Nalgumas áreas, como por exemplo, onde a irrigação é insuficiente, as culturas murcham e morrem, reduzindo assim o rendimento. $\mathrm{O}$ rendimento reduzido poderia significar lucro reduzido e aumento da pobreza. As mudanças climáticas afetam culturas ao espalhar novos tipos de doenças que não existiam no passado. Tais doenças e pragas podem ser difíceis de controlar devido a falta de remédios registados para controle de pragas.

O crescimento económico é essencial na ajuda aos incentivos para a paz e colabora para impedir a guerra, mesmo na falta de ajudas internacionais. Além de ser um fator decisivo de uma paz permanente, o crescimento económico e uma diminuição nos níveis de pobreza são primordiais de uma democracia sustentável. Deste modo, reduzir a distância entre a política de manutenção da paz e a cooperação no desenvolvimento, com destaque na mudança estrutural, é um bom método para consolidação da paz (MACHADO, 2017).

Assim, de um modo geral, durante o conflito armado, a combinação de fome, instabilidade política, pobreza e catástrofes naturais propiciam crises humanitárias complexas, na medida em 
que a fome e a insegurança tendencialmente agravam-se. Para além de que com a violência, colocase por terra, ou no mínimo dificulta-se todo o tipo de plano de ajuda, impossibilitando o acesso aos alimentos e a produção.

\section{A COVID-19 em cenários de mudanças climáticas e conflitos armados}

Depois de delinear os cenários da SAN frente às mudanças climáticas e os conflitos armados que se apresentam em África (FAO-Brasil, 2019), inclui-se neste trabalho, a COVID-19, sobretudo, dados os impactos que esta pandemia tem vindo a causar na vida dos cidadãos do mundo inteiro, tendo afetado 213 países, em menos de 6 meses.

Em entrevista, o Sociólogo moçambicano Macamo (2020, p.4) defendeu a ideia de que as estratégias que estão a ser implementadas para conter a propagação da pandemia da COVID-19 têm sido uniformizadas para praticamente todos os países do mundo. Os países decretam Estado de Emergência e obrigam os cidadãos a ficarem em casa, controlando movimentos, encerrando estabelecimentos comerciais. Mas, segundo este cientista, a reaplicação de medidas europeias não estão tendo os mesmos resultados em maior parte dos países africanos cuja maioria da população depende do setor informal.

Num país como a África do Sul, com um Estado repressivo, talvez seja possível. No Ruanda, também. Numa sociedade que teoricamente tem um Estado funcional, como em Cabo Verde, também pode ser possível, mas na maior parte dos países africanos isso é impraticável (MACAMO, 2020, p. 2).

Os líderes africanos, cujos países são membros da União Africana (AFRICAN UNION, 2020, p. 3), recentemente, deram a conhecer o seguinte:

A pandemia da COVID-19 exacerbou também outra grave crise de um surto de gafanhotos do deserto que represente uma ameaça sem precedentes à segurança alimentar e aos meios de subsistência. Enquanto muitos na África implementam as medidas preventivas contra à COVID19, de distanciamento social, ficando em casa de quarentena ou em situação de bloqueio, centena de bilhões de gafanhotos do deserto destroem os cultivos no campo, a combinação da praga de gafanhoto com a COVID19 pode acabar com qualquer sonho de segurança Alimentar, além de colocar populações inteiras sob risco de vida, especialmente na África oriental, de fome prolongada e morte, se ações urgentes não forem adotadas para lidar com a situação. 
Esse espectro pode significar, por um lado, que a região da África Oriental pode estar à beira de uma crise alimentar, se enormes quantidades de gafanhotos que devoram plantações e pastagens não forem controladas (LOCUST..., 2020). Nessa lógica, é posível que seja necessária assistência alimentar massiva, dada a rápida reprodução destes insetos que crescem exponencial e assustadoramente. Etiópia, Somália, Quénia, Tanzânia e Uganda, são alguns dos países mais afetados. No mesmo canal de comunicação, foi indicado que, esforços empreendidos até ao momento revelam-se ineficazes para controlar a infestação. A pulverização aérea de pesticidas é indicada como a maneira mais eficaz de combater os enxames, mas os países da região não têm os recursos certos (ONU News, 2020).

Por outro lado, dos pronunciamentos dos líderes africanos, se pode extrair uma tendência para a resignação e sentimento de impossibilidade para poder frear os impactos negativos da COVID-19 e de desastres de forma geral. Essa dificuldade impõe desafios significativos para todos os países, membros da União Africana, sobretudo para as famílias rurais vulneráveis, que vivem essencialmente do que produzem no seu dia-a-dia.

É, também, verdade que, quando o Estado não consegue garantir SAN, existem grandes possibilidades das suas instituições entrarem em colapso. As revoltas ocasionadas pela insegurança alimentar, podem manifestar-se na sociedade, gerando desordens, protestos, conflitos civis e oposição ao poder público, criando insegurança política e militar (MACHADO, 2017). Além da crise interna, a insegurança alimentar em conflitos armados pode levar ao aumento do problema através das migrações internas e externas, como aconteceu nalguns países africanos aqui descritos.

O certo é que atualmente, em 2020, o mundo inteiro ressente-se da evolução da pandemia de Coronavírus. Essa doença que poderá, entre estresses económicos e não só, comprometer, inclusive, o progresso em direção ao cumprimento das Metas de Objetivos de Desenvolvimento Sustentável. Em 2020, os líderes da União Africana mostraram que estão cientes dos impactos negativos que a pandemia da COVID-19 pode causar, sobretudo para a agricultura e SAN, destacando o seguinte:

Com os sistemas alimentares e agrícolas bastante intensivos em mão-deobra na maioria dos países africanos, a escassez de trabalhadores devido as restrições à mobilidade de pessoas e mão-de-obra pode comprometer o fornecimento de insumos nas atividades a montante, agrícolas e comerciais, além do processamento e transporte a jusante. Essa questão 
pode afetar todos os alimentos, mas especialmente os produtos perecíveis, vegetais, frutas e horticultura, além de carnes e laticínio (AFRICAN UNION, 2020, p. 2).

As intervenções na agricultura ajudam a manter um sistema alimentar resiliente, essencial para minimizar o impacto da pandemia da COVID-19 nas pessoas, na sociedade e na economia. E, o desenvolvimento sustentável dos sistemas agrícolas e alimentares na África tem dividendos diretos em conter as atuais influências negativas sobre a saúde pública, desemprego juvenil, educação, desenvolvimento económico e social, ao estresse resultante da migração e tendências ao envolvimento em atividades ilegais e socialmente perturbadoras (AFRICAN UNION, 2020).

Considerando os modos de vida e subsistência das comunidades rurais em África, é urgente considerar medidas de proteção das comunidades campesinas, com o mínimo de condições para que se mantenham no campo, prevendo estratégias seguras de comercialização dos seus excedentes e, ao mesmo tempo, para as famílias que dependem de recursos-extra do trabalho informal praticado nas cidades que se crie um programa emergencial de transferência de renda ou, minimamente, de doação de alimentos para que essas comunidades permaneçam seguras. As estratégias de comunicação com envolvimento das lideranças locais são fundamentais para que seja respeitado o direito à informação, e que isso resulte em medidas de proteção e de garantia da SAN.

Num olhar mais para o futuro, apesar de não existirem ainda trabalhos que falem da relação direta entre o SARS-Cov-2 e as mudanças climáticas, vários são os autores que estabelecem a relação com a saúde, informando que algumas doenças como a diarreia, malária e doenças respiratórias são passíveis de eclosão devido as mudanças climáticas (CLIMATE VULNERABLE FORUM, 2010). A título de especulação, destacamos que os principais sintomas de COVID-19 incluem febre, tosse e dificuldade para respirar (BRASIL, 2020), bem como, sintomas gastrointestinais como diarreia, vómitos e dor abdominal também, relatados para a COVID-19, assim como nas infeções por outros coronavírus (OLIVEIRA et al., 2020; ASSIRI et al., 2013).

\section{Considerações Finais}

As mudanças climáticas são uma realidade no mundo e sobretudo, nos países africanos, que se afiguram mais vulneráveis aos impactos das mudanças climáticas, decorrentes de variadas razões, entre os quais a sua relação com a natureza, ou seja, sua forma de produzir, práticas de 
cultivo e alimentares, entre outras. Não se deve menosprezar a prática do recurso ao carvão vegetal para energia, que está entre as principais causas para o desmatamento e desflorestamento.

Na história do continente africano, o Ruanda destaca-se com a ocorrência de genocídio que vitimou aproximadamente 1 milhão de pessoas, sendo as questões ambientais uma das causas mais importantes que foram apontadas para a tamanha crueldade e violência. Portanto, as mudanças climáticas também contribuem para acirradas disputas por terras. Pensar-se em ações que contribuam para a sua mitigação é, também, em parte, mais do que uma questão de sobrevivência, de alívio de tensões e conflitos violentos.

O setor da agricultura é dos setores que mais sofrem impactos das mudanças climáticas, quer através de aumento da temperatura, originando seca e a consequente escassez de água para o cultivo e para a criação de gado, quer através de tempestades tropicais que trazem consigo ventos fortes com potencial de destruição de vastas áreas de cultivo, de locais de conservação de colheita (celeiros), e sobretudo, pelos estragos causados no solo.

As mudanças climáticas e conflitos armados, já são habituais na realidade dos países africanos, e diante da COVID-19, fator que agrava ainda aquelas condições, contribuem para a fraca disponibilidade de alimentos e apresentam implicações imediatas no acesso e por fim, afeta a estabilidade de consumo de alimentos, interferindo deste modo, na situação de SAN dos locais afetados e das famílias.

\section{Referências}

AFFUL, D.B. 'Public extension agents' need for new competencies: Evidence from a climate variability study in Limpopo Province, South Africa', South African Journal of Agricultural Extension. v.44, n.2, p. 59-70. 2016.

AFRICAN UNION. Reunião de Ministros da Agricultura africanos: declaração sobre segurança alimentar e nutrição, durante a pandemia da COVID-19. Addis Ababa: FAO, African Union, 2020. Disponível em: http://www.fao.org/3/ca8655pt/ca8655pt.pdf. FAO. Acesso em: 8 jun. 2020.

ALIER, J. M. O ecologismo dos pobres. São Paulo: Contexto, 2007.

ASSIRI, A. et al. Epidemiological, demographic, and clinical characteristics of 47 cases of Middle East respiratory syndrome coronavirus disease from Saudi Arabia: a descriptive study. Lancet Infect. Dis., New York, v. 13, p. 752-761, 2013.

BORA, S. et al. Food security and conflict: World Development Report 2011, Agriculture and rural Department. Washington, DC: World Bank p. 1-27, 2010. Disponível em: 
https://openknowledge.worldbank.org/bitstream/handle/10986/9107/WDR20110031.pdf?sequenc e. Acesso em: 9 de jun. 2020.

BRASIL. Ministério da Saúde. Coronavírus: sobre a doença. Brasília: Ministério da Saúde, 2020. Disponível em: http://coronavirus.saude.gov.br/sobre-a-doenca\#transmissao. Acesso em: 19 maio 2020.

CLAY, L. A. et al. Factors associated with continued food insecurity among households recovering from Hurricane Katrina. Int. J. Environ. Res. Public Health, Basel, v. 15, n. 8, p. 1647, 2018.

CLIMATE VULNERABLE FORUM. Climate vuInerability monitor: The State of the climate crisis. Madrid: Foundation DARA International, 2010. Disponível em: https://daraint.org/wpcontent/uploads/2010/12/CVM Complete-1-August-2011.pdf. Acesso em: 9 jun. 2020.

DALLARI, D. A. Elementos de teoria geral do Estado. São Paulo: Saraiva, 2000.

DODD, W. et al. Factors associated with seasonal food insecurity among small-scale subsistence farming households in rural Honduras. Int. J. Environ. Res. Public Health, Basel, v. 17, n. 3, p. 706, 2020. DOI 10.3390/ijerph17030706.

FERREIRA, V. Barragi sta finkadu mas nós nu fica disariadu: Espaços deafrontamento entre dúvidas do presente e as incertezas do futuro na Comunidade de Boaventura, Figueira Gorda, Ilha de Santiago, Cabo Verde. RePOCS, São Luis, v. 13, n. 26, p. 107-120, 2016. Disponível em: https://www.researchgate.net/publication/341649892_QUEM_NAO_PODE_COM_A_FORMIG A_NAO_ASSANHA_O_FORMIGUEIRO_acoes_coletivas_e_formas_de_resistencia_em_defes a_de_populacoes_em_risco_de_desalojamento_em_Sao_Luis_do_Maranhao_e_em_Cabo_Verde . Acesso em: 9 jun. 2020.

FAO (Organização das Nações Unidas para Alimentação e Agricultura). Declaração de Roma sobre a segurança alimentar mundial e plano de acção da cimeira mundial da alimentação. Roma: FAO, 1996. Disponível em: http://www.fao.org/3/W3613P/W3613P00.htm\#Note1. Acesso em: 10 jun. 2020.

FAO-Brasil (Organização das Nações Unidas para Alimentação e Agricultura). Novo relatório da ONU revela que a fome na África continua aumentando. 13 fevereiro 2019. Disponível em: http://www.fao.org/brasil/noticias/detail-events/pt/c/1180521/. Acesso em: 12 junho 2020.

HOLSTI, K. J. The state, war, and the state of war. Nova York: Cambridge University Press, 1996.

INSTITUTO HUMANITAS UNISINO. A África, no Sahel, devido à seca, está se preparando para maior migração da história. São Leopoldo: IHU, 2017. Disponível em:

http://www.ihu.unisinos.br/78-noticias/569062-a-africa-no-sahel-devido-a-seca-esta-sepreparando-para-maior-migracao-da-historia. Acesso em: 10 jun. 2020.

INSURGÊNCIA em Cabo Delgado. Governo está a combater "sem conhecer dimensão real do inimigo" diz Bispo de Pemba. Moçambique para todos, Macua, 11 maio 2020. Disponível em: https://macua.blogs.com/moambique_para_todos/2020/05/insurg\%C3\%AAncia-em-cabo- 
delgado-governo-est $\% \mathrm{C} 3 \% \mathrm{~A} 1$-a-combater-sem-conhecer-a-dimens $\% \mathrm{C} 3 \% \mathrm{~A} 30$-real-do-inimigodiz-bispo-de-pemba.html. Acesso em: 3 jun. 2020.

JACOBS, C.; ALMEIDA, B. Relatório de pesquisa: propriedades e alterações climáticas: direitos e deslocados ambientais em Moçambique. Leiden: Van Vollenhoven Institute for Law, Governance and Society, 2020.

KAPTEIJNS, L. Test firing tnhe "new world order" in Somalia: the US/UN military humanitarian intervention of 1992-1995. J. Genocide Res., Basingstoke, v. 15, n. 4, p. 421-442, 2013.

KAPWATA, T. et al. Current and potential future seasonal trends of indoor dwelling temperature and likely health risks in rural Southern Africa. Int. J. Environ. Res. Public Health, Basel, v. 15, n. 5, p. 952, 2018.

LOCUST swarm: UN Warms of food crisis in Ethiopia, Kenya, Uganda, Tanzania and Somalia. BBC News, London, 14 fev. 2020. Disponível em: https://www.bbc.com/news/world-africa51501832. Acesso em: 9 Jun. 2020.

MACAMO, E. O confinamento é uma resposta europeia. Jornal Expresso das Ilhas, Cabo Verde, 3 maio 2020. p. 1. Disponível em: https:/expressodasilhas.cv/pais/2020/05/03/oconfinamento-e-uma-resposta-europeia-elisio macamo/69212. Acesso em: 9 jun. 2020.

MACHADO, A. P. A. A (in)segurança Alimentar como arma de Guerra: Somália. 2017. Trabalho de conclusão (Bacharelado em Relações Internacionais) - Universidade Federal do Pampa, Santana do Livramento, 2017. Disponível em:

https://dspace.unipampa.edu.br/bit/bitstream/riu/2461/1/Ana\%20Paula\%20Alves\%20Machado.p df. Acesso em: 9 jun. 2020.

MACK, M. Increasing respect for international humanitarian law noniternational armed conflicts. Geneva: International Committee of the Red Cross, 2008. p. 5-32.

MANJORO, A.; ROSSE, M. E. G.; FERREIRA, A. Desafios de Moçambique após os ciclones IDAI e Kenneth. Lisboa: Católica Instituto de Estudos Políticos, 2019. Disponível em: https://iep.lisboa.ucp.pt/assrt/4386/file. Acesso em: 9 jun. 2019.

MASIPA, T. S. The impact of climate change on food security in South África: current realizes and challenges ahead. Jàmbá, South África, v. 9, n. 1, 2017.

MICHLER, J.D.; TJERNSTRO, E.; VERKAART S.M. MAUSCH, K. Money Matters: The Role Of Yields And Profits In Agricultural Technology Adoption. Amer. J. Agr. Econ, v.101, n.3, p.710-731, 2018.

MOÇAMBIQUE atribui ataques no norte soldados do Estado Islâmico. Estado de Minas, Belo Horizonte, 24 abr. 2020. Disponível em: https://www-em-combr.cdn.amproject.org/v/s/www.em.com.br/app/noticia/internacional/2020/04/international,114163 2/amp.html. Acesso: 9 jun. 2020. 
MOODLEY, V.; GAHIMA, A.; MUNIEN, S. Environmental causes and impacts of the genocide in Rwanda: case studies of the towns of Butare and Cyangungu. Afr. J. Conflict Resolut., South Africa, v. 2, n. 2, p. 103-119, 2010.

MOREIRA, E.; GOUVEIA, R.; GARCIA, J.; ACOSTA, L.; BOTELHO, M:, et al.. Em tempos de pandemia. Propostas para a defesa da vida e de Direitos Sociais. UFRJ. Centro de Filosofia e Ciências Humanas. Escola de Serviço Social, Rio de Janeiro, 2020..

MUGAMBIWA, S. S.; TIRIVANGASI, H. P. Climate change: a threat towards achieveing "Sustainable Development Good number two" (end hunger achieve food security and improved nutrition and promote sustainable agriculture) in South Africa. Jamba, Durbanville, , v. 9, n. 1, p. 350, 2017. Disponível em: https://jamba.org.za/index.php/jmba/article/view/350/613. Acesso em: 9 jun. 2020.

MUKAMUHIRWA, A. et al. Concurrent drought and temperature stress in rice - A possible result of the predicted climate change: effects on yield attributes, eating characteristics, and health promoting componds. Int. J. Environ. Res. Public Health, Basel, v. 16, n. 6, p. 1043, 2019. DOI 10.3390/ijerph16061043.

MUTTARAK, R. Focusing on demographic differential vulnerability. In: Population-

Environment Research Network Cyberseminar, "Culture, Beliefs And The Environment”, 2017, Viena, Austria. Panel [...]. Viena: Wittgenstein Centre for Demography and Global Human Capital, IIASA, VID/OAW and WU, 2017. P. 1-8. Disponível em:

https://www.populationeenvironmetresearh.org/pernfiles/statements/PERN\%20Cyberseminar201 7Muttarak.pdf. Acesso em: 9 jun. 2020.

N'GOMBE, J. N.; TEMBO, M. C.; MASASI, B. “Are they aware, and why?" Bayesian analysis of predictors of smallholder Farmers. Awareness of climate change and its Risks to Agriculture. MDPI, Agronomy, Basel, v. 10, p. 376, 2020.

NILES, M.T.; SALERNO, J. D. A cross-country analysis of climate and smallholder food insecurity. Open Acess. PLoS ONE, San Francisco, v. 13, n. 1, p. 1-14, 2018.

OLIVEIRA, W.K.; DUARTE, E.; FRANCA, G.V. A.; GARCIA, L.P. Como o Brasil pode deter a COVID-19. Epidemiol. Serv. Saúde, Brasília, vol.29, n.2, p.1-8, 2020.

OMS (ORGANIZAÇÃO MUNDIAL DE SAÚDE). Report of the WHO-China Joint Mission on Coronavirus Disease 2019 (COVID-19). 2020. Disponível em:

https://www.who.int/docs/default-source/coronaviruse/who-china-joint-mission-on-covid-19final-report.pdf. Acesso em: 20 jun. 2020.

ONU (ORGANIZAÇÃO DAS NAÇÕES UNIDAS). Comentário Geral número 12, o Direito

Humano à Alimentação (Art.11). Nova Iorque: Comité de Direitos Económicos, Sociais e Culturais do Alto Comissariado de Direitos Humanos, ONU, 1999.

ONU (ORGANIZAÇÃO DAS NAÇÕES UNIDAS). Impacto da COVID-19 na África. 20 maio 2020. Disponível em: https://covid-africa-onu-maio-2020.pdf. Acesso em: 15 jun. 2020. 
ONU News. Perspectiva Global. Reportagens Humanas. FAO faz alerta para "potencial destrutivo" de nuvem de gafanhotos do deserto. 21 jan. 2020. Disponível em: https://news.un.org/pt/story/2020/01/1701271. Acesso em: 9 jun. 2020.

PARK, E.; TAGLES H. D. Epidemiologia de desastres naturales. Artigo de revisão. Rev. Tempus Actas Saúde Colect., Brasília, v. 5, n. 4, p. 11-18, 2011.

REPÚBLICA DE MOÇAMBIQUE. Conselho de Ministros. Plano diretor para a redução do risco de desastres em Moçambique para o período de 2017-2030. Maputo: Conselho de Ministros, 2017.

RODRIGUES, S. M. Segurança internacional e direitos humanos: a prática da intervenção humanitária no pós-Guerra Fria. Rio de Janeiro: Renovar, 2000.

RWANDA. Republic of Rwanda. Green growth and climate resilience: national strategy for climate change and low carbon development. Kigali: Rwanda Envirnment Management Authority (REMA), 2011. Disponível em: https://na.unep.net/siouxfalls/publications/REMA.pdf. Acesso em: 8 jun. 2020.

SCHEERENS, C. et al. Tacking adverse effects of climate change and migration through intersectoral capacity building in sub-Saharan Africa. BGJ Open, London, v. 4, n. 2, p. 1-3, 2020. DOI 10.3399/bjgpopen20X101065.

SITOE, R. Terrorismo em Moçambique? Que soluções de políticas? Um olhar aos ataques de Mocímboa da Praia. Rev. Moçamb. Est. Int., Maputo, v. 1, n. 1, p. 1-20, 2019.a

STEVENS, T. MADAN, K. Future climate impacts on maize farming and food security in Malawi. Sci. Rep. v.6, n.36241, p.1-14, 2016.

UNEP (UNITED NATIONS ENVIRONMENT PROGRAMME). Report: Emerging Issues of Environmental Concern. Nirobi: UNEP, 2016. Disponível em:

https://environmentlive.unep.org/media/docs/assessments/UNEP_Frontiers_2016_report_emergi ng_issues_of_environmental_concern.pdf. Acesso em 19 jun. $20 \overline{2} 0$.

UNIÃO AFRICANA. Nona reunião do Comité de Peritos. Industrialização para o

desenvolvimento inclusivo e transformador em África. Abuja, Nigéria, 2014. Disponível em: https://www.uneca.org/sites/default/files/uploadeddocuments/CoM/com2014/com2014e1400464 Acesso: 9 jun. 2020.

UNITED STATES AGENCY FOR INTERNATIONAL DEVELOPMENT. Southern African: Tropical Cyclones Idai 2019. Washington: USAID, 2019. Disponível em https://www.usaid.gov/cyclone-idai/fy19/fs4. Acesso: 9 jun. 2020.

WHEELER, N. J. Saving strangers: humanitarian intervention in international society. Oxford: Oxford University Press, 2000.

YAKLIN, M. Burundi: public private paternships to develop biotechnology that empowers rural farmers. Des Moines, Iwoa: The World Food Prize, 2017. Disponível em:

https://www.worldfoodprize.org/documents/filelibrary/images/youthprograms/researchpapers/20 
Buanango, Ferreira e Oliveira. SNovo Coronovórus SRS-COV-2 e...

11papers/HomeSxhoolHSYaklinMArshallEFC08774AB0877AB0AD2.pdf. Acesso em: 8 jun. 2020.

ZIEGLER, J. et al. The fight for the right to food. Geneva: Palgrave Macmillan, 2011.

ZWANE, E. M. Impact of climate change on primary agriculture, water sources and food security in western Cape, South África. Jàmbá, Durbanville, v. 11, n. 1, p. 562, 2019.

\title{
NEW CORONAVIRUS SARS-COV-2 AND THE WORSENING OF FOOD INSECURITY IN AFRICAN COUNTRIES WITH HISTORY OF CLIMATE EVENTS AND ARMED CONFLICTS
}

\begin{abstract}
In times of crisis, one of the areas heavily affected has been food, as a direct consequence of the damage caused to family farming and therefore to Food and Nutrition Security (SAN). Climate change, in turn, causes widespread crises, which, due to their impact on humanity, and above all, on SAN, provide complex humanitarian crises, worsening hunger. The military conflict imposes difficulties in access to food and production. This study aimed to critically describe the panorama of climate change and armed conflicts in Africa, relating them to the pandemic of COVID-19 as a factor of aggravating the situation of food insecurity in African countries. A literature review study was carried out in various databases, journals and portals for this purpose, with emphasis on Google Scholar, CAPES and governmental portals. The results point to climate change, as being multicausal, and constitute a risk factor for agriculture and SAN, in African countries, characterized by the destruction of crops and the reduction of food availability. Armed conflicts makes difficult to produce and distribute food, especially for people who's affected.
\end{abstract}

Keywords: Food Security; Climate changes; Africa; Pandemic; Crises.

\section{NUEVO CORONAVIRUS SARS-COV-2 Y LA AGRAVACIÓN DE LA INSEGURIDAD ALIMENTARIA EN PAÍSES AFRICANOS CON HISTORIA DE EVENTOS CLIMÁTICOS Y CONFLICTOS ARMADOS}

\begin{abstract}
Resumen
En tiempos de crisis, una de las áreas que ha sido fuertemente afectada es la alimentación, como consecuencia directa de los daños causados en la agricultura familiar y por consiguiente la Seguridad Alimentaria y Nutricional (SAN). Los cambios climáticos, a su vez originan crisis generalizadas que, por su impacto en la humanidad y, sobre todo, en la SAN, propician crisis humanitarias complejas, empeorando el hambre. El conflicto militar impone dificultades para el acceso a los alimentos y en su producción. Este estudio tuvo como objetivo describir críticamente el panorama de los cambios climáticos y conflictos armados en África, vinculando la pandemia de COVID-19 como factor de recrudecimiento de la situación de inseguridad alimentaria en países africanos. Fue realizado un estudio de revisión de literatura en varias bases de datos, periódicos y portales para tal efecto, sobresaliendo Google Académico, Portales CAPES y
\end{abstract}


gubernamentales. Los resultados señalan múltiples causas para los cambios climáticos, constituyéndose como factores de riesgo para la agricultura y la SAN en los países africanos, caracterizado por la destrucción de culturas y la disminución de la disponibilidad de alimentos. Los conflictos armados dificultan la producción y distribución de alimentos, especialmente para los afectados.

Palabras clave: Seguridad Alimentaria; Cambios Climáticos; África; Pandemia; Crisis.

\section{Agradecimento:}

Os autores agradecem ao Julian Eduardo Medina-Naranjo, pelo apoio na tradução para a língua espanhola. 